\title{
PARTICIPAÇÃO SOCIAL, SAÚDE E DESENVOLVIMENTO LOCAL: FRAGMENTOS E POSSÍVEIS COSTURAS NA GESTÃO DE POLÍTICAS PÚBLICAS
}

\author{
Maria Elisabeth Kleba da Silva*
}

\begin{abstract}
Resumo
A democratização da gestão pública no Brasil tem criado novas configurações institucionais, que representam conquistas importantes na construção de formas de governar mais próximas dos interesses e das necessidades da população. No entanto, esses fóruns têm reproduzido e reforçado a fragmentação no modo de fazer gestão pública, organizando em setores o acolhimento de demandas sociais e a produção de respostas institucionais, muitas vezes concorrentes ou sobrepostas. Esse artigo analisa dois documentos apresentados em eventos internacionais - a Carta de Ottawa para a Promoção da Saúde e a Agenda 21 - que propõem: a) uma visão integral do ser humano e de seu entorno no planejamento de estratégias e ações de caráter e interesse coletivo; b) processos participativos de decisão, reforçando a necessidade de consensos entre todos os atores sociais incluindo governo, empresas, ONGs e a população em geral - sobre as prioridades e os investimentos públicos, visando sempre a melhoria das condições de vida e a equidade social; c) a intersetorialidade, através de redes e projetos integrados que possam incluir tanto pontos de vista diferentes, quanto recursos diversificados, otimizando e potencializando a intervenção sobre problemas complexos. A democratização dos processos de gestão, garantindo-se o debate sobre sentido, conteúdo e direção das políticas públicas, requer ressignificação de espaços, papéis e relações, em todos os níveis de decisão, de produção e de sustentação de políticas e de estratégias, que podem ser favoráveis à construção social de condições e ambientes saudáveis e sustentáveis.
\end{abstract}

Palavras-chave: políticas públicas, participação social, intersetorialidade.

\footnotetext{
* Graduada em enfermagem. Doutora em Filosofia pela Universidade de Bremen - Alemanha, título convalidado como Doutora em Enfermagem pela UFSC. Professora do Centro de Ciências da Saúde e coordenadora do Grupo de Pesquisa em Políticas Públicas e Participação Social - Unochapecó. Coordenadora local do MINTER em Enfermagem - em convênio com a UFSC. E-mail: lkleba@unochapeco.edu.br.
} 


\section{Introdução}

A participação social tem sido uma bandeira de luta ao longo da história da humanidade, com diferentes focos, dependendo no entanto, do lugar e do momento de sua reivindicação. Esse movimento tem sido registrado relacionado também aos espaços de constituição das políticas públicas, quando diferentes atores sociais têm buscado garantir não apenas maior acesso a serviços e bens disponibilizados ou produzidos socialmente, mas, em especial, procurando incluir na agenda pública temas ou reivindicações - até então particulares - enquanto demandas coletivas, de forma que sejam incorporados como direitos sociais.

A luta pela democratização da gestão pública no Brasil produziu inúmeras experiências desde a constituição de 1988. Fóruns como conselhos gestores, conferências sobre políticas sociais, fóruns de desenvolvimento regional e orçamentos participativos constituíram espaços de institucionalização, como também de aprendizagem da participação social na gestão pública. Há de se reconhecer que tais espaços representam conquistas e avanços importantes na construção de formas de governar mais próximas dos interesses e das necessidades da população; no entanto, a democratização efetiva tem ainda desafios em relação tanto às práticas de gestão quanto às concepções sobre o papel da administração pública na regulação dos espaços sociais e da vida das pessoas enquanto cidadãos.

Os fóruns de gestão participativa, considerados novas configurações institucionais (NCI) de gestão das políticas públicas, são avanços à medida que as decisões do grupo que coordena o planejamento e a execução das políticas são mais facilmente conhecidas, possibilitando que diferentes atores participem do debate mas também que compreendam limites e possibilidades da administração pública. São ainda conquistas da sociedade, que tem agora espaços formais, instituídos e reconhecidos, de acolhimento de denúncias e demandas, com maior probabilidade de inclusão na agenda pública e tradução em políticas.

Quero apresentar ao debate, no entanto, o que considero um dos grandes limites desses fóruns quando defendemos que a democratização da gestão representa uma possibilidade concreta de produzir maior justiça e equidade social, favorecendo o desenvolvimento local: especialmente os conselhos gestores de políticas públicas têm reproduzido e reforçado a fragmentação das formas de pensar e de fazer da gestão pública, organizando em setores o acolhimento de demandas sociais e a produção de respostas institucionais, muitas vezes concorrentes ou sobrepostas. 
Tal prática tem como fundamento o conhecimento moderno, herança do método cartesiano que advoga a necessidade de separar os elementos de um todo para poder explicá-los a partir das supostas "objetividade científica" e "neutralidade axiológica" (BADIA; FERNANDEZ, 2008). Essa forma de produzir conhecimento, no entanto, não apenas gera uma visão limitada da realidade, mas facilita distorções na compreensão do todo, à medida que explicações pontuais e descontextualizadas inviabilizam que a reconstrução do todo a partir dos fragmentos revele a complexidade da dinâmica social que lhe dá significado.

Organizados por setor (saúde, assistência social, desenvolvimento rural) ou por temáticas transversais (direitos do idoso, da criança e do adolescente, deficientes), os conselhos gestores legitimam uma gestão que dificilmente coloca em pauta temas que problematizem a direção, os conteúdos e os sentidos das políticas públicas. A pauta dos conselhos tem priorizado o debate e a aprovação de demandas relacionadas à prestação de serviços, à deliberação sobre ações e programas focalizados e setorializados, legitimando a divisão ou mesmo a replicação de demandas dos usuários dos serviços públicos.

Esse tipo de prática tem inviabilizado que a atuação dos conselhos, na área da saúde, por exemplo, seja coerente com o que preconiza a legislação, uma vez que deliberar sobre a política de saúde implica reconhecer e deliberar sobre ações e estratégias que incidam sobre seus determinantes. Nesse sentido, a Lei n. 8080 de setembro de 1990 é clara quando estabelece "a alimentação, a moradia, o saneamento básico, o meio ambiente, o trabalho, a renda, a educação, o transporte, o lazer, e o acesso aos bens e serviços essenciais" como determinantes da saúde, e convoca Estado e sociedade civil a assumirem a responsabilidade de promovê-la, protegê-la e recuperá-la (BRASIL, 1990).

Para Ferreira e Buss (2002), embora inúmeros fatores transcendam a esfera pessoal e dependam da esfera do Estado e da sociedade organizada, os determinantes de saúde estão visceralmente ligados às condições concretas de vida, adquirindo materialidade no nível local, onde as pessoas efetivamente vivem. Assim, a promoção da saúde inclui atividades voltadas ao coletivo de indivíduos e seu ambiente (físico, social, político, econômico e cultural), através de políticas públicas intersetoriais, de ambientes favoráveis ao desenvolvimento da saúde e do reforço dos potenciais dos indivíduos e da comunidade.

A medida em que se compreende a saúde como socialmente produzida, promover saúde envolve um conjunto de valores, como equidade, democracia, cidadania, participação, solidariedade, parceria, desenvolvimento, justiça social e revalorização ética da vida 
(ANDRADE; BARRETO, 2002). Isso traz um novo significado à compreensão de seus determinantes, reconhecidos enquanto parte das dimensões sociais, econômicas, culturais e políticas "que configuram os espaços locais e mais universais nos quais as coletividades e os indivíduos vivem" (ANDRADE; BARRETO, 2002, p. 156).

Nessa perspectiva, Ferreira e Buss (2002) ressaltam que a promoção da saúde tem sido enfatizada no debate internacional como dependente de políticas econômicas, sociais e culturais abrangentes, com articulação intersetorial e parceria dos diferentes segmentos interessados na qualidade de vida. Esse esforço prevê especialmente o resgate da dívida social gerada pela desigualdade, visando cooperação para o desenvolvimento local sustentável e a equidade. Andrade e Barreto (2002) também salientam a necessidade de uma ação coordenada entre os diferentes setores sociais - incluindo o Estado, com suas políticas intersetoriais, e a sociedade civil - e o Sistema de Saúde propriamente dito como condição para a promoção da saúde. Esses autores referem ainda um "forte componente internacionalista que define a natureza política dos processos de saúde vistos do ponto de vista macroestrutural, histórico e de cumplicidade biosférica" (BUSS apud ANDRADE; BARRETO, 2002, p. 156).

A partir destas reflexões, analiso duas propostas construídas em fóruns internacionais, as quais representam alternativas de gestão que superam a fragmentação das políticas, mas que ainda não têm alcançado ressonância mais efetiva por parte dos gestores, dos técnicos e da população em geral. Essas propostas podem subsidiar não apenas o debate sobre o papel do Estado na gestão das políticas públicas determinantes das condições de vida e dos modos de viver em sociedade - mas também sobre a direção, os conteúdos e o significado dessas políticas, objeto de discussão e deliberação dos conselhos gestores.

\section{Movimentos internacionais e a constituição de uma agenda pública intersetorial}

Preocupados com a aceleração da depredação do ambiente e com o aumento das iniquidades sociais, diferentes atores ligados à gestão pública, academia ou movimentos sociais têm apresentado propostas alternativas ao desenvolvimento, muitas dessas com ênfase na sustentabilidade e na superação das injustiças sociais. Movimentos como o Greenpeace ou o Fórum Social Mundial têm chamado a atenção para a insustentabilidade dos padrões atuais de consumo e das formas de ocupação dos espaços socioambientais, propondo a necessária e possível 
reinvenção das formas de conceber e gerir a vida em sociedade, incluREVISTA GRIFOS 13 indo a administração de bens e serviços públicos.

Essas preocupações foram expressas ainda em documentos de organizações internacionais, que, através de encontros e conferências temáticas, constituem espaços oficiais para o debate e a formulação de propostas para a gestão pública. Destaco aqui dois destes encontros promovidos nas últimas décadas, cujas resoluções obtiveram adesão de gestores no Brasil: a $1^{\text {a }}$ Conferência Internacional da Promoção à Saúde, realizada em 1986 em Ottawa, Canadá e a Conferência das Nações Unidas sobre Meio Ambiente e Desenvolvimento Humano, realizada em 1992 no Rio de Janeiro, Brasil.

A $1^{\text {a }}$ Conferência Internacional da Promoção à Saúde surgiu como uma reunião temática com apoio da Organização Mundial de Saúde, reafirmando o conceito de saúde como resultado de uma construção social, ou seja, determinado pelas condições de vida das pessoas em seu local de moradia, trabalho, estudo e lazer. Nesse sentido, a Carta de Ottawa, documento assinado pelos participantes no evento, afirma como pré-requisitos da saúde a paz, a educação, a habitação, a alimentação, a renda, um ecossistema estável, justiça social e equidade (CARTA DE OTTAWA, 1986). Esse documento chama ao compromisso todos os atores sociais que de alguma forma têm influência sobre as condições de vida, e propõe como estratégia de promoção da saúde a construção de municípios ou cidades saudáveis.

Uma experiência de município e comunidade saudável começa com o desenvolvimento e/ou o fortalecimento de uma parceria entre autoridades locais, líderes da comunidade e representantes dos vários setores públicos e privados, no sentido de posicionar a saúde e a melhoria da qualidade da vida na agenda política e como uma parte central do planejamento do desenvolvimento municipal. Um componente vital deste material é construir e fortalecer alianças intersetoriais para melhorar as condições sociais e de vida nos lugares onde as pessoas vivem. (OPAS, 200-, p. 7).

A Carta de Ottawa reconhece cinco campos de atuação para a promoção da saúde: políticas públicas saudáveis; ambientes favoráveis; fortalecimento de ações comunitárias; desenvolvimento de habilidades individuais e a reorientação dos serviços de saúde, chamando especialmente atenção para o necessário diálogo e trabalho conjunto com os demais setores da administração pública (CARTA DE OTTAWA, 1986).

A Organização Panamericana de Saúde (OPAS, 200-) reflete, nesse sentido, sobre duas dimensões essenciais na implantação de um município saudável: os atores envolvidos e as estratégias para sua operacionalização. 
Para a OPAS (200-), todos os atores sociais são corresponsáveis e devem se engajar na construção de um município saudável. O governo, o poder legislativo, as organizações não governamentais, o setor privado, as instituições formadoras e os cidadãos devem assumir um compromisso público em favor da melhoria real das condições de vida e da superação de iniquidades. Apesar de reconhecer o papel decisivo do governo enquanto gestor dos interesses públicos na condução desse processo, a OPAS reforça a importância da participação comunitária, defendendo que essa participação implica envolvimento e compromisso das pessoas não apenas na identificação de necessidades e prioridades de investimentos, mas também na troca de experiências visando produzir novas formas de enfrentar coletivamente a problemática social.

Segundo a OPAS (200-), todos os países das Américas assinaram a Declaração do México (carta de compromissos da Quinta Conferência Mundial de Promoção da Saúde) no ano de 2000, reconhecendo a responsabilidade dos governantes em relação à promoção da saúde, comprometendo-se em implementar planos nacionais de ação em promoção da saúde. No Brasil inúmeros municípios divulgaram experiências - desenvolvidas em curso - relatando impactos positivos sobre as condições de vida e saúde de sua população. O Centro de Estudos, Pesquisa e Documentação em Cidades Saudáveis (CEPEDOC) da Faculdade de Saúde Pública/USP, importante referência desse movimento no Brasil - organizou em maio de 2008 o II Seminário de Efetivação da Promoção da Saúde, no Rio de Janeiro, com o objetivo de discutir processos de avaliação que pudessem subsidiar processos decisórios na promoção da saúde, tendo como apoiadores/ copromotores instituições da área da saúde reconhecidas em nível nacional e internacional, tais como o Ministério da Saúde e a Organização Panamericana de Saúde. Esse evento e as experiências relatadas em diferentes sites evidenciam que o movimento tem se mantido, especialmente através de estratégias de articulação entre gestores, órgãos de ensino e outras entidades organizadas.

Entre os principais desafios citados para a continuidade dos projetos implantados estão: a incorporação da proposta pela gestão pública como projeto de governo, o engajamento da população e práticas democráticas, transparentes e integradoras de planejamento. A efetividade dos projetos também requer processos de comunicação adequados, menos formalidades e adesão e comprometimento dos técnicos. Para Adriano e colaboradores (2000, p. 62), o ponto fundamental para o êxito da proposta "é a existência de uma efetiva comunhão de valores entre a administração municipal e a sociedade, uma disposição e uma vontade política para superar os problemas e melhorar a qualidade de vida nas cidades". 
Outra proposta de gestão integrada consta na Agenda 21, documento assinado por mais de 170 países na Conferência das Nações Unidas sobre Meio Ambiente e Desenvolvimento Humano, conhecida como Eco-92. Os países signatários se comprometeram a incorporar em suas políticas metas visando o desenvolvimento sustentável, tendo como pacto para o século 21 a formulação de um modelo de civilização em que predomine o equilíbrio ambiental e a justiça social.

A Agenda 21 está organizada em quatro seções, as quais incluem quarenta capítulos, que apresentam reflexões sobre as dimensões sociais e econômicas do desenvolvimento sustentável, a conservação e gestão dos recursos para o desenvolvimento, o fortalecimento do papel de diferentes segmentos sociais nos processos decisórios, e sobre os meios necessários para a implementação do processo. Seu conteúdo contempla a necessidade de introduzir mudanças nos padrões de produção e consumo e de promover estratégias de melhoria da qualidade de vida, incluindo ações de combate à pobreza e à miséria.

Como princípios e conceitos chaves, a Agenda 21 destaca a cooperação e parceria; a educação e o desenvolvimento individual; a equidade e o fortalecimento de grupos vulneráveis; o planejamento integrado, com prioridades e metas realistas; desenvolvimento da capacidade institucional, incluindo potenciais e competências de instituições governamentais e não governamentais; disponibilização de informações que possam subsidiar a tomada de decisão, a avaliação e o acompanhamento dos impactos das atividades humanas sobre o meio ambiente.

A organização e operacionalização de um município/uma cidade sustentável requer uma gestão que se ocupe com a sustentabilidade no uso e na ocupação do solo; com a melhoria das condições de habitação, saneamento, água, esgoto, resíduos sólidos e drenagem; com a prevenção, controle e mitigação dos impactos ambientais; com a conservação e reabilitação do patrimônio histórico; com o transporte; e desenvolvimento sustentável na relação entre economia e meio ambiente (BRASIL, 2000).

A construção de um município sustentável requer cooperação e parceria entre os vários segmentos da sociedade, entre os diferentes níveis de governo, nacional e local, e entre todos os países, numa perspectiva solidária. A Agenda 21 cita em especial a necessidade de garantir a participação das mulheres, dos jovens e das crianças, dos povos indígenas, das ONGs, dos trabalhadores e sindicatos, dos representantes da comunidade científica e tecnológica, dos agricultores e dos empresários (comércio e indústria).

Em 2000, o Ministério do Meio Ambiente publica em documento subsídios para a elaboração da Agenda 21 brasileira, reconhecendo que, "mais do que um documento, a Agenda 21 Brasileira é um 
processo de planejamento participativo que diagnostica e analisa a situação do País, das Regiões, dos Estados e dos Municípios, para, em seguida, planejar seu futuro de forma sustentável" (BRASIL, 2000, p. 7). A Agenda 21 brasileira estabelece seis áreas temáticas como eixos norteadores do debate, sendo: cidades sustentáveis; agricultura sustentável; infraestrutura e integração regional; gestão dos recursos naturais; redução das desigualdades sociais; e ciência e tecnologia para o desenvolvimento sustentável (BRASIL, 2000, p. 7).

A Agenda 21 Brasileira foi construída sob a coordenação da Comissão de Políticas de Desenvolvimento Sustentável e Agenda 21 Brasileira (CPDS), comissão paritária entre governo e sociedade civil, que tomou por base a Agenda 21 Global, mas considerou potencialidades e vulnerabilidades específicas de nossa realidade. A CPDS é presidida pelo Ministério do Meio Ambiente (MMA), que assume ainda sua secretaria-executiva, através da Coordenação da Agenda 21. A Coordenação da Agenda 21 desenvolve três ações básicas: implementação da Agenda 21 Brasileira; apoio a processos de construção e implementação de Agendas 21 locais; e formação de multiplicadores em Agenda 21 local.

A Agenda 21 local é um processo de planejamento participativo que

[...] envolve a implantação de um Fórum da Agenda 21, composto por governo e sociedade civil, responsável pela construção de um Plano Local de Desenvolvimento Sustentável, que reflita os anseios, desejos e necessidades locais por meio de projetos e ações de curto, médio e longo prazos, com os respectivos meios de implementação e as responsabilidades do governo e demais setores da sociedade local na implementação, acompanhamento e revisão desses projetos e ações (COORDENAÇÃO DA AGENDA 21, 2008).

Atualmente 117 experiências estão formalmente registradas no MMA, mas informações obtidas em visitas técnicas ou que chegam espontaneamente ao Ministério indicam um número aproximado de 600 Agendas Locais em andamento. As experiências são iniciativas governamentais, de empresas, grupos organizados da sociedade civil, universidades, entre outros (Coordenação da agenda 21, 2008). Recomenda-se que a equipe gestora formalize parceria entre o governo e a sociedade civil, criando um Fórum de coordenação e oficializando o processo, visando garantir condições políticas e institucionais necessárias para preparar, acompanhar e avaliar a construção e a implementação da Agenda 21 Local (BRASIL, 2005).

No Brasil, as iniciativas relacionadas à implantação da Agenda 21 enfrentam desafios relevantes, especialmente se considerarmos a pouca tradição de processos efetivamente participativos na elaboração 
de agendas políticas. Outro aspecto a considerar é o pouco conhecimento produzido e a insuficiência de informações relacionados aos entraves e as potencialidades de sustentabilidade no país que possam fornecer subsídios à um planejamento participativo baseado em evidências e parâmetros mais objetivos. E para finalizar,

A dificuldade imposta pela cultura dominante no Ocidente, de perceber o mundo a partir de setorialidades e/ou de reivindicações de casos particularizados, ou seja, dificuldade de criar sonhos comuns para um horizonte de tempo que vá além da vida de cada indivíduo. (ARGERICH, 2004, p. 38).

A Carta de Ottawa para a Promoção da Saúde e a Agenda 21 têm entre seus pressupostos a crença de que as condições de vida e o desenvolvimento das pessoas, comunidades e da sociedade em geral são resultantes de fatores múltiplos - sociais, econômicos culturais e ambientais - requerendo, portanto, uma visão integral do ser humano e de seu entorno no planejamento de estratégias e ações para sua melhoria. Outro pressuposto comum desses documentos é a necessidade de consensos e parcerias entre todos os atores sociais - governo, empresas, ONGs e a população em geral - tanto na decisão sobre as prioridades e os investimentos públicos, quanto no desenvolvimento de estratégias e ações visando produzir melhorias nas condições de vida e em prol de equidade social.

Os dois documentos defendem que as agendas públicas devem propor metas realistas a curto, médio e longo prazo, estabelecendo indicadores de avaliação e de acompanhamento periódico, de forma a evidenciar os avanços e subsidiar adequações necessárias. Tais indicadores são ferramentas essenciais para que os atores sociais envolvidos nos processos decisórios possam tomar decisões e propor mudanças, facilitando o diálogo entre setores e segmentos na direção de uma agenda comum para cidades/municípios sustentáveis e saudáveis.

\section{A intersetorialidade como desafio às Novas Configurações Institucionais na gestão das políticas públicas}

Analisando a Carta de Ottawa e a Agenda 21, percebemos que as transformações que elas propõem implicam ruptura com formas tradicionais de dividir papéis, de organizar estruturas, de prever espaços e relações. Implicam novas formas de gestão que deem conta da dimensão transdisciplinar de diferentes núcleos de conhecimento, sem que esses constituam novas disciplinariedades. Trazem em si a proposta de redes, considerando que 
[...] há vida onde houver uma rede que, na verdade, se compõe de um conjunto de outras redes, cujos elementos, energias e relações solidarizamse em processos poiéticos. Processos de criação e autocriação em que a interação de forças, embora contraditórias e conflituosas, não levam à destruição dos sistemas em que se expressam, mas a um movimento de ordemdesordem-interação-organização (MORIN apud MENDES; FERNANDEZ, 2008).

Para Mendes e Fernandez (2008), a possibilidade de apreensão e transformação da realidade passa pela interação de diferentes saberes e atores sociais envolvidos, o que requer esforço para o estabelecimento de relações horizontais, favorecendo o diálogo e um permanente refazer-se que atinja a todos. Isso exige, de certa forma, transgredir determinadas normas e rotinas institucionais, uma vez que a própria instituição opera na definição dos lugares de poder, exigindo dos atores respostas às especificidades, daí a produção da esperada sinergia exigir por parte desses, empenho, desejo de inovações, criatividade e certa dose de coragem (MENDES; FERRANDEZ, 2008, p. 121).

A transdisciplinaridade pressupõe uma racionalidade aberta por um novo olhar, para além e através das disciplinas, oferecendo uma nova visão da natureza e da realidade. Através do confronto entre disciplinas, a transdisciplinaridade faz emergir novos dados que as articulam entre si, sem com isso buscar o domínio sobre disciplinas, e sim, respeitando sua complementariedade (BADIA; FERNANDEZ, 2008).

É essa a perspectiva que fundamenta práticas intersetoriais como proposta de uma nova ordem governativa da cidade. A intersetorialidade busca a unidade no fazer, associada à vinculação, complementariedade e reciprocidade. Pressupõe a solidariedade para a ação completa, além da possibilidade de uma síntese gerada pela predisposição à intersubjetividade e ao diálogo, ou seja, à comunicação (MENDES, 1996).

Essa concepção coloca em cheque não apenas a forma de organização da administração pública, organizada em ministérios, secretarias ou departamentos que têm dificuldades de dialogar e muitas vezes nem conhecem a existência, o papel ou o trabalho desenvolvido pelos demais, mas e, em consequência, a forma de divisão e organização dos espaços criados para viabilizar a participação social na gestão pública, especialmente os conselhos gestores. A intersetorialidade requer a superação da lógica que divide a comunidade, famílias e pessoas de acordo com demandas de interesse disciplinar, que segrega grupos sociais por focos particularizados, retirando-os de seu contexto, obrigando-os a dispensarem tempo, esforço e recursos pessoais redobrados na busca de melhoria da qualidade de vida. 
Para Junqueira, Inojosa e Komatsu (2007), a lógica da REVISTA GRIFOS 19 intersetorialidade toma como foco a população em seu contexto de vida, reconhecendo pessoas e grupos e suas condições peculiares de vida. As prioridades são definidas a partir de problemas da população, cuja solução envolve ações integradas de vários setores. Mendes (1996) também enfatiza a necessidade de os diferentes setores, incluindo o da saúde, participarem do diálogo sobre as questões complexas da cidade que constituem riscos ou prejuízos à saúde, atuando organicamente sobre tais questões. Esta forma de gerência social requer a articulação das ações do governo sobre problemas concretos, de pessoas concretas, identificados em territórios concretos e transformados em demandas políticas.

Intersetorialidade é aqui entendida como a articulação de saberes e experiências no planejamento, realização e avaliação de ações, com o objetivo de alcançar resultados integrados em situações complexas, visando um efeito sinérgico no desenvolvimento social. Visa promover um impacto positivo nas condições de vida da população, num movimento de reversão da exclusão social. (MENDES, 1996, p. 24).

Essa concepção também está presente na Carta de Ottawa e na Agenda 21, que propõe uma lógica matricial na articulação entre os diferentes grupos locais, partindo do pressuposto de que muitos problemas que se apresentam como temas de determinado setor podem encontrar soluções mais eficazes em ações desenvolvidas por outra área (BRASIL, 2003).

Junqueira, Inojosa e Komatsu (1997) consideram o município como espaço particularmente apropriado para integrar as ações intersetoriais. Esse processo não é apenas de construção de novas identidades, mas também de aprendizagem de novos paradigmas, os quais informam a mudança das práticas institucionais. Essa nova lógica viabiliza a identificação de problemas e potencialidades dos grupos populacionais relacionados à padrões de qualidade de vida que refletem direitos de cidadania, promovendo a interferência transdisciplinar, intencional e monitorada, nas questões que estão no espaço de governabilidade do poder público, especialmente em nível local.

Campos (apud COMERLATTO, 2007) considera que a ação intersetorial, como um processo organizado e coletivo, não pode ser espontânea. Trata-se de uma ação deliberada que requer o respeito à diversidade e às particularidades de cada setor ou participante. Envolve espaços comunicativos, capacidade de negociação e intermediação de conflitos para a resolução ou enfrentamento final do problema principal e para a acumulação de forças, na construção de sujeitos, na descoberta da possibilidade de agir. 
Para Comerlatto e colaboradores (2007), a intersetorialidade representa um espaço potencial de compartilhar saberes e poder, de estruturar novas linguagens, novas práticas e novos conceitos, não estabelecidos ou suficientemente experimentados, sendo um desafio crucial também aos conselhos gestores. Isso requer dos sujeitos envolvidos uma nova forma de perceber, compreender e avaliar as políticas públicas, superando manifestações pontuais descontextualizadas do conjunto das políticas.

Nessa perspectiva, Correia (2005) enfatiza como desafio aos conselhos gestores a articulação das estratégias e ações com setores e políticas de outras áreas. Para ela, a agenda dos conselhos deve contemplar uma pauta de propostas e lutas que visem a construção de uma política pública, universal e de qualidade, articulada à luta geral pela transformação da sociedade.

Pontual (2003) ressalta a vontade política dos diferentes atores envolvidos na gestão como um dos principais desafios da intersetorialidade. Do governo requer alterações do desenho institucional de poder, exigindo descentralização territorial e administrativa, transparência das informações, e matricialidade das ações, integrando atividades de várias secretarias e/ou programas num mesmo território. Também requer do governo uma definição clara dos conselhos gestores como canais importantes para compartilhar a gestão, necessitando mecanismos que superem a gestão que cada secretaria exerce sobre o conselho da sua área. À medida que os conselhos sejam reconhecidos como instâncias efetivas e reais de democratização da gestão política, deve haver por parte do governo uma política de acompanhamento do conjunto dos conselhos, ou seja, promovendo discussões sobre diretrizes comuns, propondo agendas e processos de capacitação partilhados.

Por outro lado, a intersetorialidade requer dos movimentos sociais e organizações civis a superação da fragmentação das reivindicações, muitas vezes coorporativas, bem como a constituição de fóruns e redes que viabilizem o debate sobre agendas comuns mais amplas, reconhecendo temas articuladores.

Pontual (2003) sugere como estratégia articuladora construir indicadores comuns para o planejamento de políticas sociais, bem como realizar diagnósticos participativos integrados. Ele cita como exemplos os indicadores de qualidade de vida ou inclusão social que preveem uma série de informações integradas, promovendo modos de pensar as questões de forma mais abrangente. Conceitos como saúde ou moradia requerem informações mais abrangentes, articulando variáveis que envolvem a pessoa e o contexto no qual ela se insere. 
A Cidade Saudável e a Agenda 21 têm em suas propostas esse REVISTA GRIFOS 21 potencial articulador, na medida em que defendem a democratização da gestão pública e a intersetorialidade como diretriz para o planejamento e a execução das políticas. A comissão intersetorial ou o fórum da Agenda 21 representam espaços articuladores de políticas e, em meu ponto de vista, deveriam ser constituídos como conselhos gestores da cidade/município, tendo os conselhos gestores setoriais como comissões temáticas. O conselho gestor da cidade/município viabilizaria um trabalho articulado tanto no diagnóstico da situação de vida quanto no planejamento e no acompanhamento da implementação de estratégias e ações intersetoriais, voltadas à melhoria da qualidade de vida, à equidade, à justiça social e à sustentabilidade.

Esse espaço deve ainda se constituir não mais como espaço restrito à reivindicação, mas como parceiro, corresponsável na construção da realidade social, reunindo diferentes atores e setores da sociedade. Espaço de explicitar conflitos e de consensuar prioridades, de debater o sentido e o conteúdo das políticas e ressignificar papéis e relações sociais. Sem eximir o papel do Estado na coordenação do debate, do planejamento e da execução das políticas públicas, esse formato de nova constitucionalidade institucional traz um potencial de democratizar não apenas o processo deliberativo, mas também de reinventar a forma de fazer política, assegurando-a como pública, saudável e sustentável.

\section{Considerações finais}

A participação social tem se consolidado na gestão pública através de diferentes fóruns, em especial os conselhos gestores, órgãos deliberativos e fiscalizadores de sua execução. Apesar de seus avanços, esses conselhos têm reproduzido a lógica de fragmentação da administração pública, segregando demandas a partir de lógicas disciplinares e setoriais.

Compreendemos que as propostas apresentadas tanto pelo movimento de Cidades Saudáveis quanto na Agenda 21 são modelos de gestão com potencial de superar essa fragmentação, na defesa do princípio da integralidade, como concepção de política, e da diretriz da intersetorialidade como lógica de organização e funcionamento dos serviços públicos.

Ambas propostas defendem como estratégias de organização e operacionalização de um município saudável/sustentável o planejamento estratégico, incluindo acompanhamento e avaliação dos resultados de forma a garantir adequações ao longo do processo. Além da intersetorialidade, 
reforçam a necessidade de parcerias entre setor público, setor privado e organizações da sociedade, através de redes e projetos integrados que possam incluir tanto pontos de vista diferentes, quanto recursos diversificados, otimizando e potencializando a intervenção sobre problemas complexos.

Apesar de sua consistência em relação ao desenho do modelo de gestão, em relação aos atores, as estratégias e as etapas do processo, essas propostas ainda não tem conseguido provocar maior ressonância entre gestores, técnicos e sociedade em geral para que sejam assumidas como política de governo e modelo de desenvolvimento local para além de algumas experiências isoladas. Outro desafio que considero relevante é a aproximação das duas propostas como modelo unificado, colocando o espaço local e o cidadão como foco central do desenvolvimento e da melhoria das condições de vida e saúde.

A viabilização e a promoção da intersetorialidade requer diálogo entre os atores que coordenam, apoiam e executam essas duas propostas, visando a produção de uma agenda única. A democratização dos processos de gestão, garantindo-se o debate sobre sentido, conteúdo e direção das políticas públicas, requer ressignificação de espaços, papéis e relações seja em nível local, seja na esfera dos ministérios, órgãos de produção, de promoção e de sustentação de políticas e de estratégias, que podem ser favoráveis à construção social de condições e ambientes saudáveis e sustentáveis.

\section{Referências}

ADRIANO, Jaime Rabelo et al. A construção de cidades saudáveis: uma estratégia viável para a melhoria da qualidade de vida? Ciência \& Saúde Coletiva, v. 5 , n. 1, p. $53-62,2000$.

ANDRADE, Luiz Odorico Monteiro de; BARRETO, Ivana Cristina de Holanda Cunha. Promoção da saúde e cidades/municípios saudáveis: propostas de articulação entre saúde e ambiente. In: MINAYO, Maria Cecília de Souza; MIRANDA, Ary Carvalho de (Orgs.). Saúde e ambiente sustentável: estreitando nós. Rio de Janeiro: Fiocruz, 2002.p. 151.

ARGERICH, Eloísa Nair de Andrade. Desenvolvimento sustentável, direito ambiental e bioética: legislação, educação e cidadania. Caxias do Sul: EDUCS, 2004.

BADIA, Denis Domeneghetti; FERNANDEZ, Juan Carlos Aneiros. Intersetorialidade e polarização paradigmática. Gestão local nos territórios da cidade. p. 124-132. Ciclo de Atividades com as Sub-Prefeituras, São Paulo. Disponível em: < http://www.cidadessaudaveis.org.br/artigo_juan_denis.pdf $>$. Acesso em: 26 mar. 2008. 
BRASIL. Ministério do Meio Ambiente. Cidades sustentáveis: subsídios à REVISTA GRIFOS 23 elaboração da Agenda 21 Brasileira. Brasília: MMA/IBAMA/Consórcio Parceria 21 IBAM-ISER-REDEH, 2000.

. Ministério do Meio Ambiente. Construindo a Agenda 21 local. Brasília: MMA, 2003.

Lei n. 8080, de 19 de setembro de 1990. Dispõe sobre as condições para a promoção, proteção e recuperação da saúde, a organização e o funcionamento dos serviços correspondentes e dá outras providências. Diário Oficial da União; Poder Executivo, 20 set. 1990.

. Ministério do Meio Ambiente. Passo a passo da Agenda 21. Brasília: MMA/Secretaria de Políticas para o Desenvolvimento Sustentável, 2005.

CARTA DE OTTAWA para a Promoção da Saúde. In: PRIMEIRA CCONFERENCIA INTERNACIONAL DE PROMOÇÃO DA SAÚDE, Ottawa, 1986.

COMERLATTO et al. Gestão de políticas públicas e intersetorialidade: diálogo e construções essenciais para os conselhos municipais. Revista Katál, Florianópolis, v. 10, n. 2, p. 265-271, jul./dez. 2007.

COORDENAÇÃO DA AGENDA 21. A Agenda 21 no Brasil. Brasília: MMA/Coordenação da Agenda 21,2008. (Mimeografado).

CORREIA, M. V. C. Desafios para o controle social: subsídios para capacitação de conselheiros de saúde. Rio de Janeiro: Fiocruz, 2005.

FERREIRA, José Roberto; BUSS, Paulo Marchiori. O que desenvolvimento local tem a ver com a promoção da saúde? In: ZANCAN, Lenira; BODSTEIN, Regina;

JUNQUEIRA, Luciano Antonio Prates; INOJOSA, Rose Marie; KOMATSU, Suely. Descentralização e intersetorialidade na gestão pública municipal no Brasil: a experiência de fortaleza. In: XI CONCURSO DE ENSAYOS DEL CLAD - "El Tránsito de la Cultura Burocrática al Modelo de la Gerencia Pública: Perspectivas, Posibilidades y Limitaciones" -, Caracas, 1997. Disponível em: <http://unpan1.un.org/intradoc/groups/public/documents/CLAD/ UNPAN003743.pdf>. Acesso em: 21 nov. 2007.

MARCONDES, Willer B. Promoção da saúde como caminho para o desenvolvimento local: a experiência em Manguinhos - RJ. Rio de Janeiro: ABRASCO/FIOCRUZ, 2002. p. 15-38.

MENDES, Eugênio Vilaça. Uma agenda para a saúde. São Paulo: HUCITEC, 1996.

MENDES, Rosilda; FERNANDEZ, Juan Carlos Aneiros. Práticas intersetoriais para a qualidade de vida na cidade. Gestão Local nos Territórios da Cidade. Ciclo de Atividades com as Sub-Prefeituras, São Paulo, p. 117-123. Disponível em: < http://www.cidadessaudaveis.org.br/artigo_rosilda_juan.pdf $>$. Acesso em: 26 mar 2008. 
OPAS - Organização Panamericana de Saúde. Municípios e comunidades saudáveis: guia dos prefeitos para promover qualidade de vida. Organização Panamericana da Saúde/Divisão de Promoção e Proteção à Saúde, [200-] .

PONTUAL, Pedro. Caminhos possíveis para a articulação entre os conselhos. In: SOUTO, Anna Luiza Salles; PAZ, Rosangela (Orgs.). Observatório dos direitos do cidadão: acompanhamento e análise das políticas públicas da cidade de São Paulo. SEMINÁRIO ARTICULAÇÃO ENTRE OS CONSELHOS MUNICIPAIS, 12, 2003, São Paulo. Anais... São Paulo: Instituto Polis/Puc-SP, 2003.p. 11-20.

\begin{abstract}
The democratization of public management in Brazil had been creating new institutional layouts, that represent important reaches in the construction of new forms to govern closer to the interests and the needs of the population. However, these forums had reproduced and reinforced the fragmentation of the way to do public management, organizing in sectors the reception of social demands and the production of institutional responses, many times competitors or overlapped. This article examines two documents presented in international events Ottawa charter for health promotion and Agenda 21 - that proposes: a) an integral vision of the human being and its surrounding in the planning of strategies and actions of collective sent and interest; b) participative processes of decision, reinforcing the need of consensus among the social actors - including government, enterprises, ONGs and the general population - about the priorities and the public investments, always aiming to improve of life conditions and social equality; c) the intersectoriality, by the webs and different projects integrated that may include different points of view and different resources, improving and potentializing the intervention on complex problems. The democratization of management processes, ensuring the debate about sense, content and direction of public policies, requires new meanings for the spaces, roles and relations, in all levels of decision, of reproduction and support of policies and strategies, that may be favorable to the social construction of healthy and sustainable conditions and ambients.
\end{abstract}

Keywords: public policies, social participation, intersectoriality. 